\title{
Considering Ergonomics in the Planning of Tugger Train Systems for Production Supply
}

\author{
Christopher Keuntje , Michael Kelterborn and Willibald A. Günthner \\ Institute for Materials Handling, Material Flow, Logistics, Technical University of Munich, 85748 Garching, Germany
}

\begin{abstract}
For the planning of a production supply using a tugger train system, no holistic methods are available that allow one to factor in all important criteria that influence the decision-making process. This paper investigates the possibilities for the consideration of ergonomics in the system design of tugger train systems, based on an empirical study with 42 test subjects. Three basic concepts of tugger trains used in the German automotive industry are defined and evaluated regarding ergonomics. With the aid of a software-based model for tugger trains, which takes the whole life cycle of the tugger train system into account, the economic feasibility of found ergonomic advantages is analyzed. Furthermore, it is exemplarily shown how an informed decision about technical details of a tugger train system can have a positive impact on the ergonomics and economics of the system.
\end{abstract}

\section{Introduction}

In the automotive industry, tugger train systems (TTS) play a vital role in the supply of the production and are used throughout the major OEMs. Tugger trains (TT) are manually operated industrial trucks driving continuously on fixed routes and - analogous to a bus in passenger transport - stop at destinations where a filled load carrier has to be supplied or an empty one has to be collected. This allows a high-frequency just-in-time supply of material and, therefore, the synchronization of the material flows and the assembly cycle. As a result, a significant improvement of key performance indicators, like the material throughput time, can be gained [1].

Despite the widespread use of TT, no standards have been implemented yet, and a large variety of techniques is used [2]. In a study conducted with partners of the German automotive industry, 26 TTS were analyzed. Based on similarities regarding additionally needed technical elements and the required handling steps for the supply of load carriers, the classification of [3] was adapted, and three basic concepts for TT were derived.

The classic TT concept is the trailer concept, in which the load carriers (e.g. pallet cages) are supplied to the production on the trailer itself. In contrast, in a taxi concept, the load carriers are supplied on additional trolleys that are transported by the wagons of the TT. The third basic concept for TT is the roller conveyor concept, where the load carriers are placed on roller conveyors installed on the TT wagons. To be able to supply the load carriers, permanently installed roller conveyors are additionally needed in the production. In Table 1 , the introduced concepts are exemplarily illustrated by specific technical implementations of the concepts.
In addition to the introduced concepts and various technical implementations of these concepts, different operating processes and control strategies lead to a high amount of design possibilities for a TTS. In combination with various interdependencies between the TT and other elements before and after in the material flow, the planning of those systems is a complex task.

So far, no method exists that allows for a holistic planning of TTS, factoring in all criteria that should be regarded in the decision-making process [2]. In order to develop such a method, the impact of changes in the system design on these criteria has to be researched in detail to provide a significant support to the planner.

A criteria, often underrepresented in the decisionmaking process, is the ergonomics of a TTS. Ergonomics are a sensitive issue because, in a TTS, the manual handling of load carriers with weights of $600 \mathrm{~kg}$ and more can lead to a high amount of physical stress for the workers. This is especially critical considering the demographic change. An aging workforce puts high pressure on the German automotive industry, as they must be able to provide a suitable work environment [5].

On the basis of the challenge presented, this paper researches how ergonomics can be taken into account in detail in the planning of a TTS.

\section{Brief literature review}

In [6] and [7] the modeling of combined routing and scheduling problems is used to reduce e.g. the number of TT; the specifics of the TT and the ergonomics are not regarded. 
Table 1. Exemplary representation of technical implementations of tugger train concepts (c.f. [4]).

\begin{tabular}{|c|c|c|c|}
\hline Concept name & $\begin{array}{c}\text { Schematic representation } \\
\text { (specific technical implementation) }\end{array}$ & $\begin{array}{c}\text { Element used for production } \\
\text { supply of the load carrier }\end{array}$ \\
\hline Trailer concept & Taxi concept & &
\end{tabular}

A model for the calculation of an ideal cycle time, presented in [8], takes temporal and ergonomic restrictions into account, without regarding the technical implementation of the TT.

Regarding ergonomics, [9], [10], and [11] research the maximum acceptable weights and forces for pushing and pulling activities, focusing on the physical stress of workers; different technical designs of the handled trolleys were not analyzed in these works.

Orientating tests in companies, as described in [12], can be used for the evaluation of a specific case, but, due to various differing parameters, they can hardly be compared among themselves.

In summary, with works on TT focusing on partial aspects of the planning and works on ergonomics not factoring in alternative technical specifications, no method exists that allows for the consideration of ergonomics in detail in the system design of a TTS.

\section{Ergonomic evaluation of basic tugger train concepts}

In order to allow for an in-depth ergonomic evaluation of different TTS and, in this way, support the specific system design, a comprehensive test series was conducted. In this empirical study, a multi-component piezoelectric hand force measuring system was used. This allows for the measurement of the three orthogonal components of the acting force, which has to be applied by a worker in a tugger train system. Details on the methodology and experimental procedures of the study, conducted with 42 test subjects, have been published in [13]. The most significant ergonomic assessment factor, determined in the study, is the initial force - the force a worker has to apply for the pushing and pulling tasks in a TTS. The initial force is calculated based on a definition of the IFA by the 95th percentile of the data for the total force [12]. Based on the results of the study and data of another test series, performed in cooperation with the IFA and a German manufacturer of sports cars [14], the initial force is shown in Fig. 1 dependent on the weight of the load carriers for the basic TT concepts. The displayed graphs are based on mean values over various technical implementations of the concepts used in the empirical study.

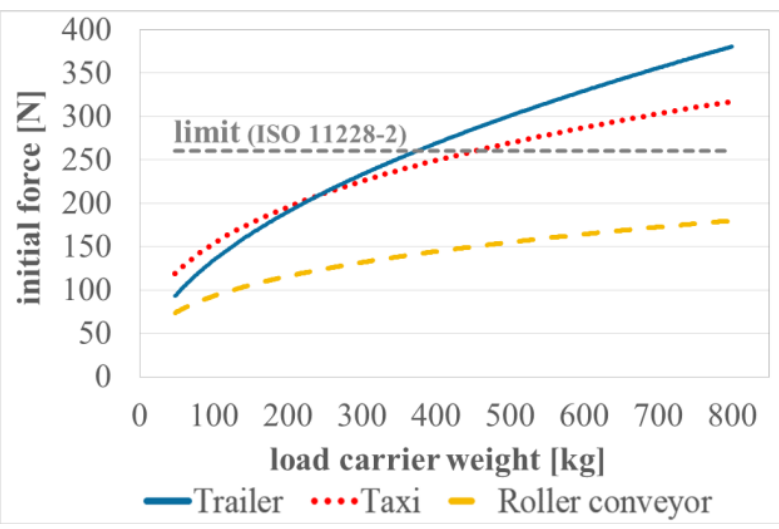

Figure 1. Correlation of load carrier weight and initial force.

The given limit of the initial force, recommended by the ISO 11228-2, takes a frequency of one pushing/pulling task every five minutes into account [15]. The stated weight only factors in the load carrier itself; additionally, the analysis takes the weight of the wagon or trolley into account.

While the roller conveyor concept can be used for weights of $800 \mathrm{~kg}$ and more, the recommended limit of the initial force is reached at $460 \mathrm{~kg}$ for the taxi concept, and $375 \mathrm{~kg}$ for the trailer concept.

After demonstrating the differences of the basic TT concepts regarding ergonomics, in the next section it is investigated whether the pointed out ergonomic advantages are economically feasible.

\section{Economic feasibility of ergonomic findings concerning basic tugger train concepts}

The economic evaluation of the basic TT concepts is done using a software-based model that, like the 
conducted empirical study, was developed in the research project IntegRoute [16]. Said model is an analytical model that allows for a complete dimensioning of a TTS. Therefore, the model, for example, contains a detailed calculation of the space requirement, cycle time, and personnel deployment of a TTS. On that basis, the total project costs are derived, performing a dynamic investment calculation that, for instance, takes the discounting of future cash flows and a rise in personnel costs into account.

Using the software-based model requires various input parameters. Therefore, based on the study conducted in the German automotive industry analyzing 26 TTS, an automotive production plant with characteristics close to the mean values of the examined systems was selected. As a result, the following analysis can be considered a close estimation for many production plants. In a plant with completely different characteristics, the findings should be verified using the exact input parameters.

In the selected TTS, 300 different items in load carriers are supplied to the production line, creating a throughput of 1500 load carriers per day. The weight of the load carriers is around $500 \mathrm{~kg}$. The average length of a tour is 400 meters, and for every item two load carriers are present at the production line all the time. Based on said characteristics, Figure 2 shows the correlation of the project duration and the total project costs.

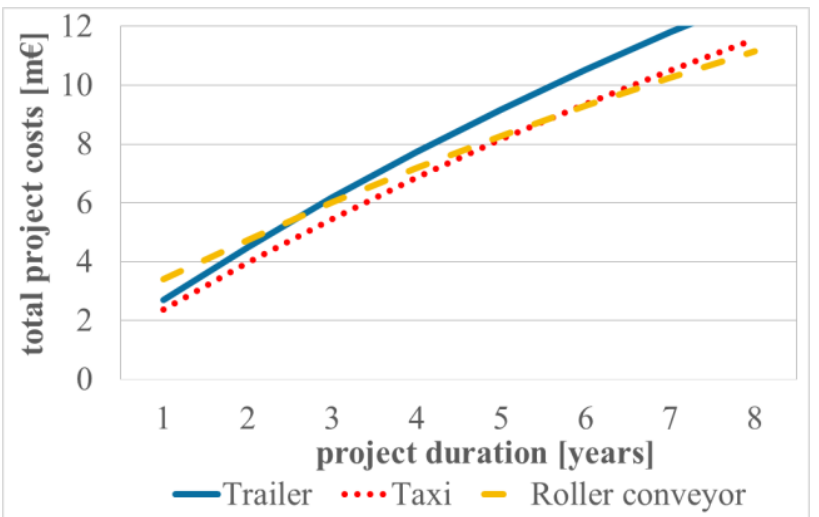

Figure 2. Correlation of project duration and total project costs.

While the highest investment for the additionally needed roller conveyors could have been expected, it is worth emphasizing that the trailer concept - which wagons are technically less sophisticated and because of that reason less expensive than the wagons in the taxi concept - leads to a higher investment than the taxi concept. While for the trailer concept a separate trailer is required to be placed at the production line for every load carrier, in the taxi concept, technically simpler trolleys are used for the placement of the load carriers. Therefore, the high amount of trailers, equipped with a clutch and costly casters made for being towed, increases the investment significantly.

Comparing the taxi concept and the roller conveyor concept in the analyzed planning scenario, after about 5.6 years the project costs equal one another. The cause is the shorter time for the exchange of load carriers in the roller conveyor concept, which leads to lower personnel costs per year.

In the automotive industry, with logistics projects being attributed to specific vehicle projects with model cycles of 6 to 8 years, the high investment for a roller conveyor concept can very well be compensated by the lower personnel costs per year.

The ergonomic evaluation of the roller conveyor concept has shown uncritical values even for load carriers with weights of $800 \mathrm{~kg}$ and above; therefore, there is no need for further consideration. For the taxi concept it is worth taking a closer look at different technical implementations of the concept. For this reason, the next section focuses on the taxi concept analyzing the effects of technical changes to the trolley, regarding the ergonomics and economics of the TTS.

\section{Comparison of different trolleys used in a taxi concept}

In this section, utilizing the data of the empirical study and the developed software-based model, different trolleys used in a taxi concept are compared for a project duration of six years. The regarded trolleys differ in configuration and material of castors used, as these factors exert the highest influence on the regarded TTS. In Table 2, the effects on ergonomic and economic key performance indicators are displayed for different trolleys. While most of the indicators are commonly used, the vibration factor $\beta$ has to be explained; $\beta$ was defined by the authors in [13], and is a dimensionless figure that indicates a disturbance for the worker with values above approximately 30 . Based on (1), $\beta$ is calculated using the values of the total force $y(n)$, which are measured in a frequency of $50 \mathrm{~Hz}$.

$$
\beta=\frac{M V\left|y(n)-\frac{1}{3} \sum_{i=n-1}^{n+1} y(i)\right|}{M V(y(n))} * 4000
$$

while the initially regarded trolley A exceeds the recommended limit of $260 \mathrm{~N}$, for the trolley $\mathrm{B}$, the initial force is reduced to $253 \mathrm{~N}$, due to a change in the configuration of castors. Furthermore, the existence of two fixed castors leads to a reduction of the cycle time by 0.4 minutes, which adds up to a significant decrease of investments and, as a consequence, of the total project costs.

Comparing trolley $\mathrm{B}$ with trolley $\mathrm{C}$, a further decrease of the initial force and the cycle time is possible by changing the material of the castor from polyurethane with a Shore hardness of 96 to polyamide.

Beside the reduction of the initial force, the change of material leads to an increase of vibrations, causing a significant disturbance for the worker while pushing or pulling. Despite these contrasting ergonomic indicators, in the empirical study the castors made of polyurethane were preferred by the test subjects and only 13.5 percent favored the castors made of polyamide. 
Table 2. Influence of technical specifics of trolleys on ergonomics and economics.

\begin{tabular}{|c|c|c|c|c|}
\hline \multicolumn{2}{|c|}{ Factor } & Trolley A & Trolley B & Trolley C \\
\hline \multirow{3}{*}{$\begin{array}{c}\text { Specifics of the } \\
\text { trolley }\end{array}$} & Configuration of castors & 4 swivel castors & $\begin{array}{c}\text { 2 fixed castors } \\
\text { 2 swivel castors }\end{array}$ & $\begin{array}{c}2 \text { fixed castors } \\
\text { 2 swivel castors }\end{array}$ \\
\cline { 2 - 5 } & Material of castors & Polyurethane (96 Shore) & Polyurethane (96 Shore) & Polyamide \\
\hline \multirow{4}{*}{$\begin{array}{c}\text { Key performance } \\
\text { indicators }\end{array}$} & Initial force [N] & 272 & 253 & 231 \\
\cline { 2 - 5 } & Vibration factor $\beta[-]$ & 18 & 19 & 44 \\
\cline { 2 - 5 } & Cycle time [min] & 13.6 & 13.2 & 13.1 \\
\cline { 2 - 5 } & Investments [m€] & 0.414 & 9.397 & 0.369 \\
\cline { 2 - 5 } & Total project costs [m€] & 9.26 & 9.06 & 9.10 \\
\hline
\end{tabular}

\section{Conclusion}

This paper analyzes three basic concepts for tugger trains used in the German automotive industry regarding ergonomics, and it shows that - when using the roller conveyor concept - load carriers with a weight of $800 \mathrm{~kg}$ and more can be manipulated trouble-free; in other concepts, the weight per load carrier should not exceed $500 \mathrm{~kg}$. Furthermore, it is shown that concepts with advantages regarding ergonomics do not automatically lead to higher total project costs. Therefore, the improvement of ergonomics and economics can go hand in hand.

Furthermore, the paper demonstrates the positive influence of a trolley with two fixed castors on the ergonomics and, through reduced handling time, also on the economics of a tugger train system. Regarding the material of the castors, the positive and negative characteristics of two examined materials are pointed out.

The findings of this paper show that it is possible to consider ergonomics in an early stage of the system design. A future integration of these findings in a planning method is an important step closer to a holistic planning of tugger train systems.

\section{Acknowledgement}

This paper received funding by the $\mathrm{AiF}$ (no. $18136 \mathrm{~N}$ ), within the program for sponsorship by Industrial Joint Research (IGF) of the German Federal Ministry of Economic Affairs and Energy based on an enactment of the German Parliament.

\section{References}

1. J.P. Womack, D.T. Jones, Lean Thinking, Simon \& Schuster (1996)
2. W.A. Günthner, S. Galka, E. Klenk, T. Knössl, M. Dewitz, Results of a study, Institute for Materials Handling, Material Flow, Logistics. Technical University of Munich (2012)

3. C. Baerwolff, VDI-Report no. 2136 (2011)

4. The Association of German Engineers: VDI Standard 5586 (2016)

5. C. Loch, F. Sting, N. Bauer, H. Mauermann, Harvard Business Review, 88, 3, p. 99-102 (2010)

6. S. Emde, N. Boysen, European Journal of Operational Research 217, p. 287-299 (2011)

7. B.S. Vaidyanathan, J.O Matson, D.M Miller, J.E. Matson, IIE Trans. 31, 11, p. 1083-1092 (1999)

8. M. Droste, J. Deuse, Proceedings of the 4th CARV (2011)

9. S. Snook, V.M. Ciriello, Ergonomics, 34, 9, p. 11971213 (1991)

10. M.J. Hoozemans, P.F. Kuijer, I. Kingma, J.H. van Dieen et al., Ergonomics 47, 1, p. 1-18 (2004)

11. V.M. Ciriello, P.G. Dempsey, R.V. Maikala, N.V. O’Brien, Ergonomics 51, 5, p. 593-601 (2008)

12. U. Glitsch, M. Post, I. Hermanns, DGUV Report 2/2014, p. 77-81. (2014)

13. C. Keuntje, J. Heiß, P. Gangkofner, W.A. Günthner, Proceedings of the 11. Hamburg conference on forklifts, p. 139-156 (2016)

14. U. Glitsch and R. Ellegast: Explorative Messungen der Handkräfte beim Ziehen und Schieben von Schleppwagen. Usage approval granted by Dr.-Ing. h.c. F. Porsche AG (2013)

15. International Organization for Standardization, Ergonomics - Manual handling - Part 2: Pushing and pulling. ISO 11228-2 (2007)

16. W.A. Günthner, C. Keuntje, Research report IntegRoute. Institute for Materials Handling, Material Flow, Logistics, Technical University of Munich (2016). 